\title{
Thermal Analysis of Oil Shale Ash-filled High-density Polyethylene Composites
}

\author{
Raid Banat", Heba Alkhlaifat and Alaa Al-Shurafat \\ Department of Chemistry, Al al-Bayt University, P.O.BOX 130040, AL-Mafraq \\ 25113, Jordan.
}

Received: $14^{\text {th }}$ March 2021;

Accepted: $5^{\text {th }}$ June 2021

\begin{abstract}
Thermal analysis was performed to evaluate the impact of the addition of oil shale ash (OSA) to high-density polyethylene (HDPE) polymer matrix using differential scanning calorimetry (DSC) and thermo-gravimetric analysis (TGA). Extrusion and press molding processes were used to compound the OSA-filled HDPE polymer composites containing $0,5,15$ and 25 wt\% OSA, for which the thermal properties and the characteristics of the composites were studied. Investigation of the thermal properties of the OSA-HDPE composite is necessary for selecting processing conditions and the appropriate application field. The DSC results demonstrated that OSA addition only marginally affected the glass transition temperature $T_{g}$ of the composite formulations. The melting temperature $T_{m}$ showed a decreasing trend with increased OSA fraction, while the crystallization temperature $\mathrm{T}_{\text {cryst }}$ showed an increasing trend. The heat of fusion $\Delta \mathrm{H}_{\mathrm{m}}$, the heat of crystallization $\Delta \mathrm{H}_{\text {cryst }}$ and the percentage of crystallinity decreased on the addition of OSA filler. The TGA results demonstrated that the thermal stability of the polymer composite matches that of the neat polymer behavior up to $350{ }^{\circ} \mathrm{C}$ after which the thermal stability of the filled polymer composite increases with increased filler content. Above 360 ${ }^{\circ} \mathrm{C}$, the weight loss of the neat polymer as well as of the polymer composite is accelerated up to $4800^{\circ} \mathrm{C}$ where all tested samples become fully degraded.
\end{abstract}

Keywords: Oil shale ash, HDPE, DSC, TGA, Thermal properties.

\section{Introduction}

In the last four decades, oil shale became an important developing energy resource. Countries such as the USA, China, Russia, Estonia and Germany, are already producing energy from oil shale, while others have accelerated efforts to utilize the ore ${ }^{[1-3]}$. Oil shale ash (OSA) is produced as a by-product of the oil shale combustion process ${ }^{[4-5]}$. One of the main negative environmental impacts of the oil shale industry is the polluted wastewater produced during the mining and ash moisture stages. Oil shale combustion produces large amounts of ashes which are usually deposited in landfills. OSA carries serious risks to the bio-system, such as the hazardous trace elements as well as high alkalinity to the groundwater ${ }^{[6,7]}$. Attempts were made to utilize OSA in concrete and asphalt pavement ${ }^{[8-10]}$. Fly ash has been used as a filler in few polymeric materials ${ }^{[11-13]}$, OSA is also used in some patented works as a reinforcement material ${ }^{[14-16]}$. Generally, Rubber, low-density polyethylene (LDPE) and polypropylene (PP) are among the polymer matrices where fly ash is used as a filler ${ }^{[17-19]}$.

Fillers are added to polymer composites to improve several desired properties ${ }^{[20-22]}$. Fillers can improve the dimensional stability, enhance the thermal and electrical insulation and modify the mechanical performance of the filled polymer composites ${ }^{[23-25]}$. Commercial fillers, such as calcium carbonate, silica, talc and carbon black, are already being used in polymeric composite materials. Moreover, fly ash has been incorporated in polymeric materials to improve 
mechanical, thermal and electrical performance $^{[26-30]}$. Utilizing OSA waste will reduce both the negative impact on the environment and the landfill expenses.

In this study, OSA-filled high-density polyethylene (HDPE) composite material was formulated and investigated. The thermal behavior of the OSA-HDPE composite as a function of the filler content was evaluated using DSC and TGA. Thermal parameters, including the glass transition temperature $T_{g}$, the melting point $T_{m}$, the crystallization temperature $T_{\text {cryst }}$, the enthalpy of melting $\Delta \mathrm{H}_{\mathrm{m}}$, the heat of crystallization $\Delta \mathrm{H}_{\text {cryst }}$, the degree of crystallinity $\left(X_{C} \%\right)$, the degradation temperature and the weight loss of the composite samples, were studied and reported herein.

\section{Materials and Methods}

The investigated polymer composites were compounded using HDPE (ExxonMobil HDPE HMA 018) as the polymer matrix and OSA as a filler material. OSA was obtained from the incineration of the oil shale rocks obtained from the Attarat region in Jordan. The oil shale deposit was subjected to crushing and grinding using a Pulverisette 9 vibrating cub mill (Fristch, Germany). The sieved powder was then incinerated in a muffle furnace at $600{ }^{\circ} \mathrm{C}$ for $2 \mathrm{~h}$. To determine the particle size of the dry oil shale ash, a sample was sieved and kept in desiccator for further use. To evaluate the chemical composition, the sample was analyzed by X-ray fluorescence (XRF), Philips X'Pert PW 3060, operated at $45 \mathrm{kV}$ and $40 \mathrm{~mA}$. The bulk density was measured according to a standard method using a high-precision graduated cylinder to measure the volume of $50 \mathrm{~g}$ OSA after drying at $80{ }^{\circ} \mathrm{C}$ for $24 \mathrm{~h}$, followed by weighing the powder sample. To determine the moisture content, the sample was placed in furnace at $103 \pm 2{ }^{\circ} \mathrm{C}$ for $48 \mathrm{~h}$. The moisture content was measured using Equation (1):

$$
\text { Moisture content } \%=\frac{w t_{o}-w t}{w t_{o}} \times 100 \%
$$

where $w t_{0}$ and $w t$ stand for the weight of the specimen before and after drying, respectively.

\section{Composite Processing}

HDPE and OSA were premixed and compounded using a parallel co-rotating twinscrew extruder (TSE 20, L/D: 40:1, diameter 22 $\mathrm{mm}, 8 \times 78 \mathrm{~mm}^{2}$ flat die) with the temperature profile: $160{ }^{\circ} \mathrm{C} / 180{ }^{\circ} \mathrm{C} / 180{ }^{\circ} \mathrm{C} / 175{ }^{\circ} \mathrm{C} / 175$ ${ }^{\circ} \mathrm{C} / 180{ }^{\circ} \mathrm{C} / 180{ }^{\circ} \mathrm{C}$. The extruded OSA-HDPE composite was then press-molded in the form of sheets using a digital hot-press machine (XH406B) at $160{ }^{\circ} \mathrm{C}$. The press molding time was fixed at $20 \mathrm{~s}$. The OSA filler content of the composites varied from $0 \mathrm{wt} \%$ to $25 \mathrm{wt} \%$.

\section{Thermal Analysis}

To study the effect of the addition of OSA on the thermal behavior of HDPE, DSC analysis was performed according to the ASTM E 473-85 standard method using a NETZCH DSC 204 Phoenix ${ }^{\circledR}$ ASC instrument. Test specimens weighing 9-13 mg of the OSA-HDPE composite were used. Each specimen was heated to $150{ }^{\circ} \mathrm{C}$ at a rate of $10^{\circ} \mathrm{C} / \mathrm{min}$ where the temperature was kept constant for 3 min and then cooled to -130 ${ }^{\circ} \mathrm{C}$ at a rate of $10{ }^{\circ} \mathrm{C} / \mathrm{min}$ to trace the crystallization process and go down below the expected polymer $T_{g}$ value. The specimen was again reheated up to $150{ }^{\circ} \mathrm{C}$ to record the $\mathrm{T}_{\mathrm{g}}$ and $\mathrm{T}_{\mathrm{m}}$ values. The step-change in the heat flow and the maximum of the endotherms were taken as $\mathrm{T}_{\mathrm{g}}$ and $\mathrm{T}_{\mathrm{m}}$, respectively. The exotherm was taken as $\mathrm{T}_{\text {cryst. }}$ The enthalpies of melting were calculated from the integrated phase transition area. Thermograms from the cooling curve of the non-isothermal crystallization behavior were investigated under constant cooling rate. All the heating-cooling runs were performed under nitrogen at a flow rate of $50 \mathrm{~mL} / \mathrm{min}$ to prevent the oxidation of the sample. The determined melting enthalpy was used to evaluate the degree of crystallinity $\left(X_{C}\right)$, based on the total composite weight, according to Equation 2:

$$
X_{C}=\frac{\Delta H_{m}}{\Delta H_{o}} \times 100 \%
$$

where $\Delta \mathrm{H}_{\mathrm{m}}$ is the melting enthalpy of the sample in $\mathrm{J} / \mathrm{g}$ and $\Delta \mathrm{H}_{\mathrm{o}}$ is the melting enthalpy of a $100 \%$-crystalline form of HDPE $(293 \mathrm{~J} / \mathrm{g})$.

The TGA/SDTA 851e thermal analyzer from Mettler Toledo was used to perform TGA tests for the selected specimens. Test specimens weighing approximately $5-10 \mathrm{mg}$ were scanned from $20^{\circ} \mathrm{C}$ to $500{ }^{\circ} \mathrm{C}$ under nitrogen with a flow rate of $30 \mathrm{~mL} / \mathrm{min}$ at a heating rate of $10^{\circ} \mathrm{C} / \mathrm{min}$. Weight loss and onset degradation temperature were determined from the TGA curves.

\section{Results and Discussion}

Figure 1a represents a photograph of the oil shale rocks from the Attarat region in Jordan. 
Upon incineration, OSA is produced of which an SEM micrograph is presented in Figure $1 b$. Some of the physical characteristics of OSA are listed in Table 1. OSA is grey in color and the major element constituents are $\mathrm{Ca}, \mathrm{Si}$ and $\mathrm{Fe}$.
OSA-HDPE composites with OSA fraction up to $25 \%$ were prepared (Table 2). The grey color of the composite sheet samples becomes deeper as the loading of the grey filler increases, thus affecting the light transmittance behavior of the composite.
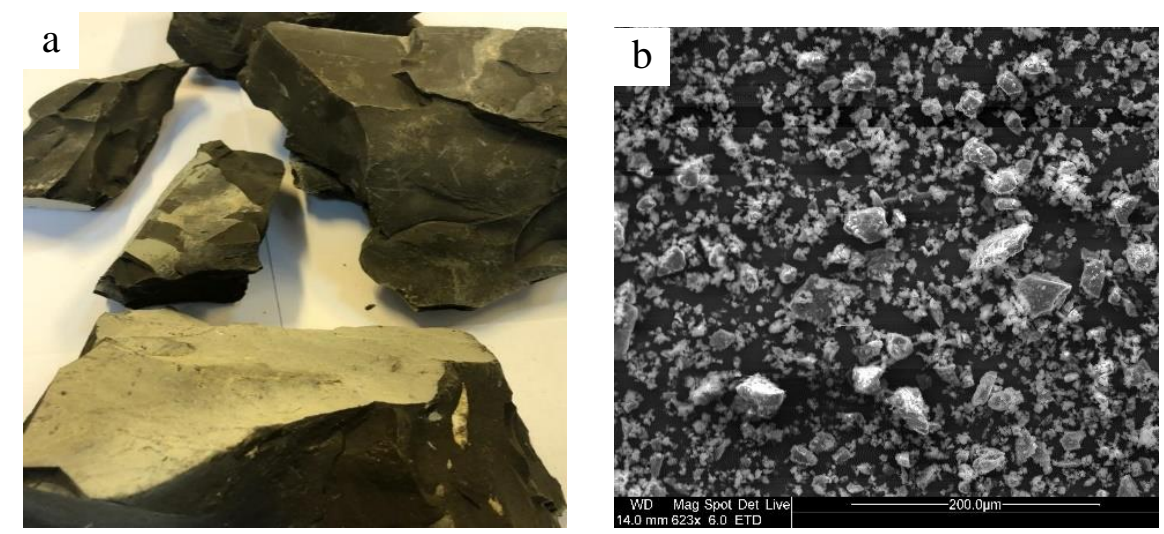

Figure 1. a) Photograph of the oil shale rocks from the Attarat region in Jordan, b) SEM micrograph of the oil shale ash (OSA).

Table 1. Physical characteristics of OSA.

\begin{tabular}{ccccc}
\hline Major components & Bulk density $\left(\mathbf{g} / \mathbf{c m}^{3}\right)$ & Moisture content $(\%)$ & Particle size $(\boldsymbol{\mu m})$ & Color \\
\hline $\mathrm{Ca}, \mathrm{Si}, \mathrm{Fe}$ & 0.945 & $<1$ & $<65$ & Grey \\
\hline
\end{tabular}

Table 2: Formulation of OSA-HDPE composites.

\begin{tabular}{ccccc}
\hline Specimen & Neat HDPE & 5 \% OSA-HDPE & 15 \% OSA-HDPE & 25 \% OSA-HDPE \\
\hline OSA (wt $\%$ ) & 0 & 5 & 15 & 25 \\
HDPE (wt $\%)$ & 100 & 95 & 85 & 75 \\
\hline
\end{tabular}

The crystallization temperature $\left(\mathrm{T}_{\text {cryst }}\right)$ and the heat of crystallization $\left(\Delta \mathrm{H}_{\text {cryst }}\right)$ of the OSAHDPE composites were extracted by DSC measurements from the first cooling curve. The heat of the crystallization of neat HDPE, obtained from the integrated area under the cooling curve, was found to be $195 \mathrm{~J} / \mathrm{g}$. The corresponding exothermic sharp peak was centered near $111.2{ }^{\circ} \mathrm{C}\left(\mathrm{T}_{\text {cryst }}\right)$, Figure 2 .

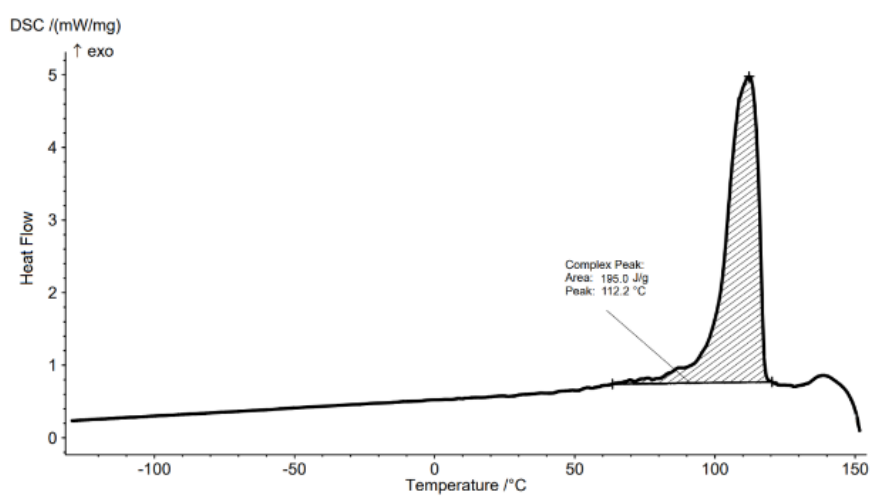

Figure 2. $T_{c}$ and $\Delta H_{\text {cryst }}$ of the neat HDPE. 
The DSC thermographs of $0,5,15$ and 25 wt $\%$ OSA-filled HDPE are presented in Figure 3. The thermal parameters related to $\mathrm{T}_{\mathrm{g}}, \mathrm{T}_{\mathrm{m}}$ and $\Delta \mathrm{H}_{\mathrm{m}}$ were collected from the second heating curves. The endothermic step change and the peak for HDPE and the polymer composites were attributed to $T_{g}$ and $T_{m}$, respectively. The integrated area belonging to the endotherm corresponds to $\Delta \mathrm{H}_{\mathrm{m}}$.

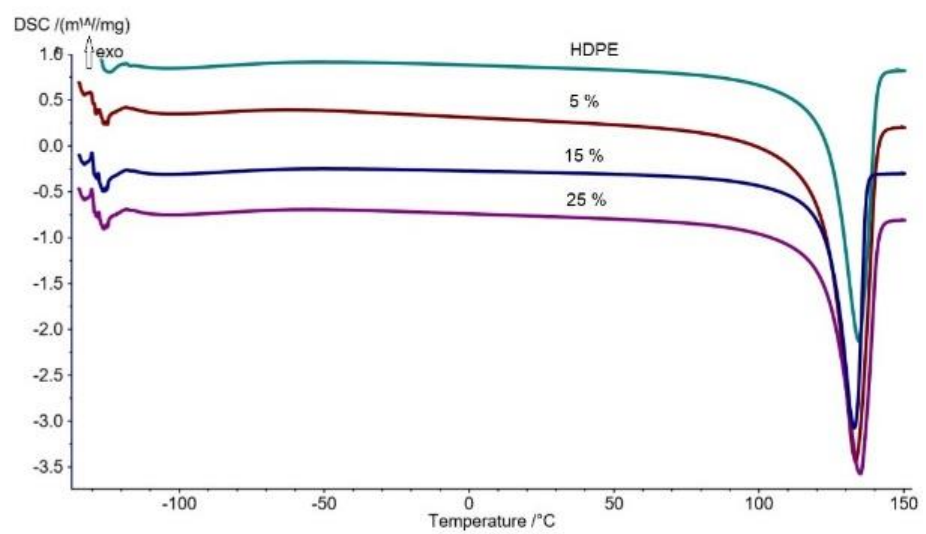

Figure 3. $T_{g}$ and $T_{m}$ of the neat HDPE and the OSA-HDPE composites.

The thermal behavior of the composite samples was almost similar to that of neat HDPE, while the transition steps and peaks of the polymer composites had their positions being deviated from that of neat HDPE. As can be seen in Figure $4 \mathrm{a}$, the glass transition temperature of the OSA-HDPE composites is not significantly different from that of neat HDPE. The dispersion of OSA in the HDPE matrix seems not to affect the chain-free volumes and the plasticity of the polymer composite, which are both related to the change in the $T_{g}$ value. An increase in the chainfree volumes will result in a decreased $\mathrm{T}_{\mathrm{g}}$ value and vice versa. The same relation applies to the plasticity of the polymer chains.

Non-isothermal crystallization of the OSAHDPE composite was processed at a cooling rate of $10{ }^{\circ} \mathrm{C} / \mathrm{min}$. For neat HDPE and the OSAHDPE composites, the crystallization temperatures were $113.1,114.9$ and $115.1^{\circ} \mathrm{C}$, respectively, as shown in Figure 4c. The crystallization temperatures of the OSA-HDPE composites had higher values compared to neat HDPE. This indicates that crystallization becomes easier or that the crystal size becomes smaller, upon increasing the filler content. The isothermal and non-isothermal crystallization kinetics of some polymer composites were extensively reported $^{[35]}$. The energy barrier for non-isothermal crystallization was found to vary with the presence of the filler. The nucleation process and the activity of the filler particles in the polymer matrix were proved to have an effect, up to a certain loading level, depending on the filler type, size and distribution ${ }^{[36]}$.
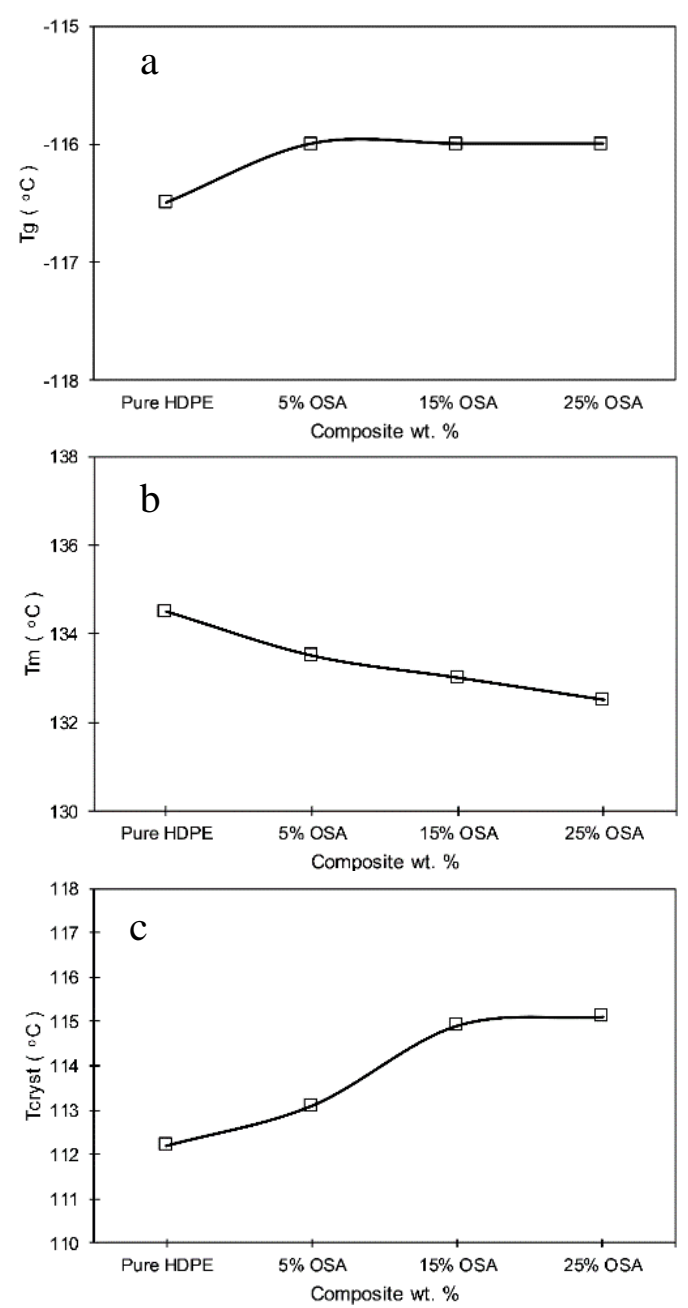

Figure 4. The effect of the OSA-filler content on a) $T_{g}$, b) $T_{m}$ and c) $T_{\text {cryst }}$ of the OSA-HDPE composite. 
The enthalpy of melting of fully crystalline HDPE was $293 \mathrm{~J} / \mathrm{g}$. The $\Delta \mathrm{H}_{\mathrm{m}}$ values for the OSA-HDPE composites declined with increased filler loadings, as shown in Figure $5 \mathrm{a} . \Delta \mathrm{H}_{\mathrm{m}}$ at 25 wt\% OSA significantly decreased to $172.5 \mathrm{~J} / \mathrm{g}$, which indicates that less thermal energy is required for the polymer fusion process as the filler loading is increased, which can be attributed to the decreased degree of crystallinity upon the addition of OSA ${ }^{[37]}$.

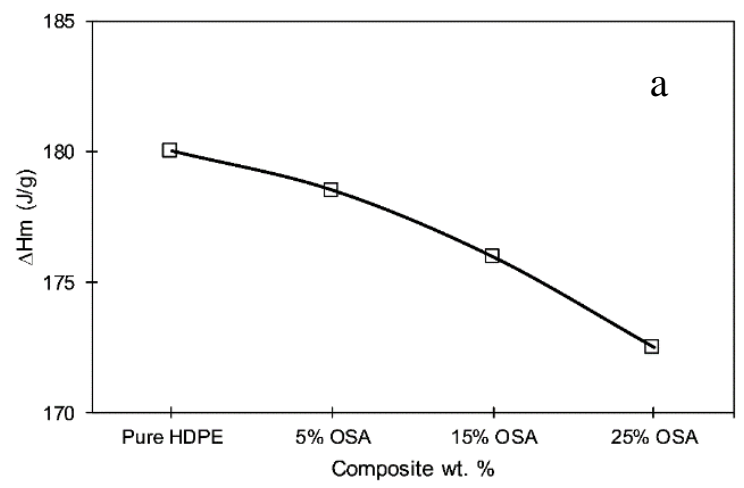

Figure 5. Effect of the OSA-filler content on a)

The crystallinity is the relative amount of small- and long-ordered arrangement of the macromolecular chains in the polymer matrix. DSC was used to investigate the crystallinity\% of HDPE upon the addition of OSA-filler (Figure 6). The crystallinity\% was extracted from the area under the DSC heating thermographs. The degree of crystallization of HDPE in the OSAHDPE composites was shown to decrease as the filler loading increased. The addition of OSA to the polymer matrix reduced the percent crystallinity. This agrees with the results reported for an inorganic filler-filled polylactide composite, where the crystallization process was hindered with increased filler content ${ }^{[39]}$. Also,

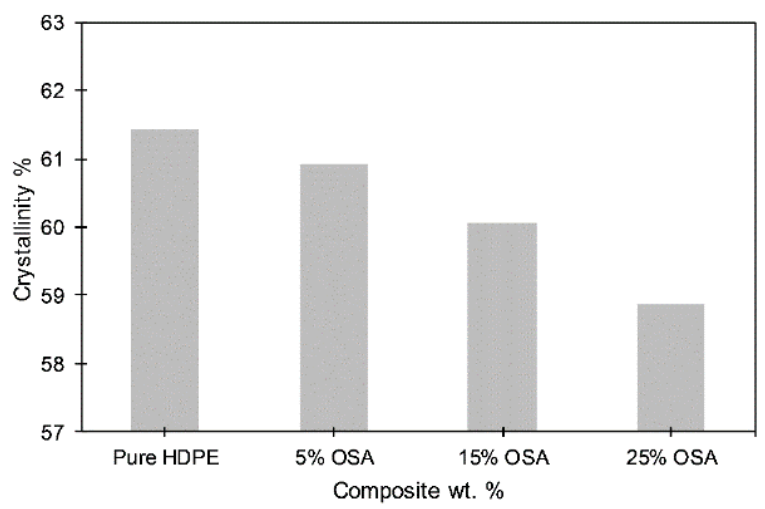

Figure 6. Effect of OSA-filler content on the crystallinity\% of the OSA-HDPE composite.
The heat of crystallization of HDPE as a function of the OSA-filler content is shown in Figure 5b. Increasing the OSA filler loading level causes a decrease in the heat of crystallization of the polymer composite. The lowest heat of crystallization was observed when the filler content was highest. Similarly, kaolinfilled polypropylene with an increased filler content showed a shift in the crystallization peak to higher temperatures and a reduction in the crystallization time was also reported ${ }^{[38]}$.

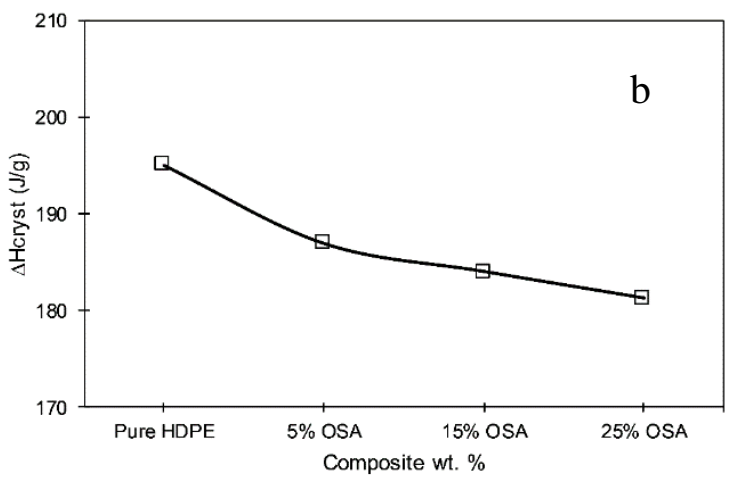

m and b) $\Delta H_{\text {cryst }}$ of the OSA-HDPE composite.

the observed change in $\mathrm{T}_{\mathrm{m}}, \Delta \mathrm{H}_{\mathrm{m}}$ and $X_{c}$ agrees well with literature report on the thermal behavior of fly ash-filled polyethylene composite material ${ }^{[40,41]}$. The crystallinity of the HDPE phase was reduced on adding fly ash, which was attributed to the inhibited close packing of the polymer chains. This also indicates good interactions of the various components of the polymer composite ${ }^{[42]}$.

The filler content can have an important effect on the end-use properties, such as thermal expansion and stiffness of the final composite material. The amount of filler present in the composite material in some cases can be determined by TGA. The TGA thermal decomposition data can be used to predict the useful product lifetimes and thermal stability.

The TGA analysis was performed on the neat HDPE and the OSA-HDPE composites. The high thermal stability of the OSA-filler is shown in Figure 7, where the weight loss of OSA can be seen to remain constant as a function of temperature within the tested temperature range; i.e., up to $500{ }^{\circ} \mathrm{C}$. Figure 7 also shows that filler addition thermally stabilizes the HDPE matrix. While the neat HDPE is thermally stable up to $340{ }^{\circ} \mathrm{C}$, the composites are thermally stable up to $350{ }^{\circ} \mathrm{C}$, after which thermal degradation starts taking place. Moreover, the composite with $25 \%$ OSA is thermally stable up to $360{ }^{\circ} \mathrm{C}$, 
representing thus an enhancement of the composite material end-use properties. The obtained results are in good agreement with the previously published work by Deepthi ${ }^{[42]}$.

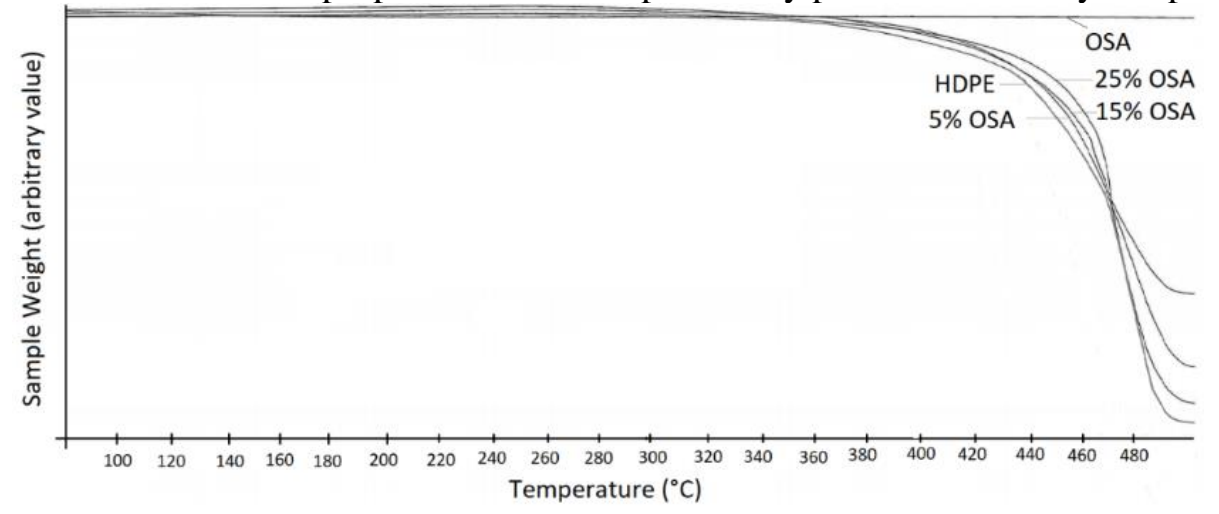

Figure 7. TGA of the OSA-HDPE composite with various filler weight fractions.

\section{Conclusions}

Due to its high thermal stability, the addition of OSA to HDPE can alter the thermal degradation behavior of HDPE in the composite, as confirmed by TGA. According to DSC and TGA analyses, the good dispersion of OSA in the HDPE matrix affected the measured thermal parameters, such as $T_{c}$ and $T_{m}$ as well as the degradation temperature. High filler loading levels $(25 \%)$ decrease the melting point, while the crystallization temperature $\mathrm{T}_{\text {cryst }}$ increases with increased filler content, indicating that the crystallization process begins on cooling at an earlier time compared to the neat polymer. The OSA addition is expected to act as a nucleation promotor, but with small crystal size growth, as suggested by reduced percent of crystallinity. Furthermore, the increase in the OSA loading level leads to decreased $\Delta H_{m}$ values as well as decreased $\Delta \mathrm{H}_{\text {cryst }}$ values due to the decrease in the polymer fractions in the composite matrix. The crystallinity percent of HDPE in the composite matrix was shown to decrease as the filler loading is increased, since the filler would restrict the mobility of the HDPE polymer chains. Finally, the OSA-HDPE can be considered as a thermally stable composite material, where the degradation temperature and the weight loss of the composite matched values higher than those of the neat HDPE polymer. The thermal behavior study of the OSA-HDPE composite is important to select the optimum processing conditions and to target the appropriate application area for the present composite formulation.

\section{References}

[1] Abu El-Rub, Z.; Kujawa, J.; Albarahmieh, E.; Al-Rifai, N.; Qaimari, F.; Al-Gharabli, S., Energies, 2019, 12, 3148 (16 pages).

[2] Smadi, M. M.; Haddad, R. H., Cem. Concr. Compos., 2003, 25, 43-50.

[3] Baum, H.; Bentur, A.; Soroka, I., Cem. Concr. Res., 1985, 15, 391-400.

[4] Bentur, A.; Ish-Shalom, M.; Ben-Bassat, M.; Grinberg, T., Special Publication, 1986, 91, 779-802.

[5] Baum, H.; Soroka, I.; Bentur, A., Cem. Concr. Res., 1985, 15, 303-314.

[6] Usta, M. C.; Yörük, C. R.; Hain, T.; Paaver, P.; Snellings, R.; Rozov, E.; Gregor, A.; Kuusik, R.; Trikkel, A.; Uibu, M., Minerals, 2020, 10, 765 (10 pages).

[7] Gao, J., Coal, Oil Shale, Natural Bitumen, Heavy Oil and Peat, Encyclopedia of Life Support Systems, Jinsheng, G., Ed., (EOLSS), 1996.

[8] Ish-Shalom, M.; Bentur, A.; Grinberg, T., Cem. Concr. Res., 1980, 10, 799-807.

[9] Gromko, G. J., Transp. Res. Rec., 1975, 549, $47-54$.

[10] Bentur, A.; Ish-Shalom, M.; Grinberg, T., Cem. Conc. Res., 1981, 11, 175-182.

[11] Salah, N.; Alfawzan, A. M.; Saeed, A.; Alshahrie, A.; Allafi, W., Sci. Rep., 2019, 9, $1-13$. 
[12] Blanchard, P.; Elgoyhen, J. P.; Karth, B.; Müller, H.; Spehn, J.; Brunner, M.; Tinkl, M., Mineral Material Powder with High Dispersion Ability and Use of Said Mineral Material Powder, US Patent Application No. 16/412,011, 2019.

[13] Achterberg, R. R., Plastic Material Comprising Fy Ash As a Filler, Method for Preparing Such Material and Use of Fly Ash As a Filler in Plastic Materials, Patent Application No. NL2010047C2, 2014.

[14] Viikna, A.; Krumme, A.; Reinok, A.; Kuusik ,R.; Kaljuvee, T., Composite of Polymeric Material with Mineral Fillers, Patent Application No. WO2012083972A1, 2012.

[15] Viira, I., Polymeric Composite Material Containing Burnt Oil Shale Fly Ash and the Method for the Preparation thereof, Patent Application No WO2017182043A1, 2017.

[16] Viira, I.; Kiil, T.; PVC Composition Material That Contains Oil Shale Ash and a Product Made from the Said Material, Patent Application No. WO2011098091A1, 2011.

[17] Qihai, X., China Plast., 2000, 14, 48-53.

[18] Hashmi, S. A. R.; Sharma, P.; Chand, N., J. Appl. Polym. Sci., 2008, 107, 2196-2202.

[19] Patel, J. B.; Patel, M. R.; Sharma, S.; Dave, E. B.; John, N.; Patel, J. V., Pop. Plast. Packag., 2007, 52, 96-100.

[20] Sepet, H.; Aydemir, B.; Tarakcioglu, N., Polym. Bull., 2019, 77, 3677-3695.

[21] Kaya, G. G.; Deveci, H., Thermochim. Acta, 2020, 689, 178637 (11 pages).

[22] Limami, H.; Manssouri, I.; Cherkaoui, K.; Saadaoui, M.; Khaldoun, A., J. Build. Eng., 2020, 30, 101251 (24 pages).

[23] Kuljanin, J.; Vučković, M.; Čomor, M. I.; Bibić, N.; Djoković, V.; Nedeljković, J. M., Eur. Polym. J., 2002, 38, 1659-1662.

[24] Weidenfeller, B.; Höfer, M.; Schilling, F. R., Compos. Part A-Appl. Sci. Manuf., 2004, 35, 423-429.

[25] Bare, W.; Albano, C.; Reyes, J.; Dominguez, N., Surf. Coat. Technol., 2002, 158, 404-407.
[26] Awad, A. H.; El-Wahab, A. A. A.; ElGamsy, R.; Abdel-latif, M. H., AIN SHAMS Eng. J., 2019, 10, 353-358.

[27] Latip, N. A.; Sofian, A. H.; Ali, M. F.; Ismail, S. N.; Idris, D. N. D., Mater. Sci. Eng., 2020, 736, 052009 (7 Pages).

[28] Dang, Z. M.; Zhang, Y. H.; Tjong, S. C., Synth. Met., 2004, 146, 79-84.

[29] Yang, L.; Schruben, D., Polym. Eng. Sci., 1994, 34, 1109-1114.

[30] Chand, N.; Jain, D., J. Appl. Polym. Sci., 2006, 100, 1269-1276.

[31] Al-Samhan, M.; Al-Attar, F.; Al-Fadhli, J.; Al-Shamali, M., Polymers, 2021, 13, 1389 1397.

[32] Lule, Z. C.; Shiferaw, EW.; Kim, J., Polymers, 2020, 12, 418-426.

[33] Alvarez, V. A.; Pérez, C. J., J. Therm. Anal. Calorim., 2011, 107, 633-643.

[34] Lin, Z.; Mai, K., Polym. Plast. Technol. Eng., 2007, 46, 417-420.

[35] Zou, P.; Tang, S.; Fu, Z.; Xiong, H., Int. J. Therm. Sci., 2009, 48, 837-846.

[36] Papageorgiou, G. Z.; Achilias, D. S.; Bikiaris, D. N.; Karayannidis, G. P., Thermochim. Acta, 2005, 427, 117-128.

[37] Dorigato, A.; Pegoretti, A.; Frache, A., $J$. Therm. Anal. Calorim., 2012, 109, 863873.

[38] Jikan, S. S.; Ariff, Z. M.; Ariffin, A., J. Therm. Anal. Calorim., 2010, 102, 10111017.

[39] Vidović, E.; Faraguna, F.; Jukić, A., J. Therm. Anal. Calorim., 2016, 127, 371380.

[40] Chinh, N. T.; Trang, N. T.; Mai, T. T.; Giang, N. V.; Trung, T. H.; Huynh, M. D.; Hoang, T., Vietnam. J. Chem., 2017, 55, 709-714.

[41] Biglari, S.; Kole, M.; Dubey, T. Indian J. Phys., 2011, 85, 559-573.

[42] Deepthi, M. V.; Sharma, M.; Sailaja, R. R.; Anantha, P.; Sampathkumaran, P.; Seetharamu, S., Mater. Des., 2010, 31, 2051-2060. 